\title{
Oxygen mass transfer and hydrodynamic behaviour in wastewater: determination of local impact of surfactants by visualization \\ techniques.
}

5 Authors: Mélanie Jimenez ${ }^{\mathrm{a}, \mathrm{b}, \mathrm{c}, \mathrm{d}}$, Nicolas Dietrich ${ }^{\mathrm{a}, \mathrm{b}, \mathrm{c}, \mathrm{d}}$, John R. Grace ${ }^{\mathrm{e}}$, Gilles Hébrard a,b,c,d *

* Corresponding author: Gilles Hébrard, hebrard@insa-toulouse.fr

$$
\text { +33561359435 }
$$

10

a Université de Toulouse, INSA, UPS, INP, LISBP, 135 Av. de Rangueil, F-31077 Toulouse, France

b INRA UMR792, Ingénierie des Systèmes Biologiques et des Procédés, F-31400 Toulouse, France

15 c CNRS UMR 5504, Ingénierie des Systèmes Biologiques et des Procédés, F-31400 Toulouse, France

d Fédération de Recherche FERMAT, CNRS, Toulouse, France

e Department of Chemical and Biological Engineering, Univerity Of British Columbia, Vancouver, Canada V6TIZ3

Abstract

Powerful techniques, based on the Planar Laser Induced Fluorescence (PLIF) technique, are deployed to locally visualize and quantify the impact of surfactants in wastewaters on hydrodynamics and oxygen mass transfer. Bubble diameter, aspect ratio, rise velocity, contamination angle, as well as flux, flux density, liquid side mass transfer and diffusion coefficients of transferred oxygen are determined based on these techniques applied in the wake of rising bubbles of diameter $1 \mathrm{~mm}$ and through planar gas/liquid interfaces. The initial experiments were performed in demineralized water containing small amounts of surfactant. Different concentrations of surfactant were added to finally reach the Critical Micelle Concentration (CMC). Bubbles have classically been found to be more spherical with a reduced rise velocity in the presence of surfactants up to the CMC. Above the $\mathrm{CMC}$, these hydrodynamic 
characteristics were found to be almost constant, although the oxygen mass transfer decreased due to the presence of surfactants. Experimental results were markedly lower than predicted by the well-known Frössling equation with rigid surfaces. This is believed to be caused by a barrier of surfactants hindering the oxygen mass transfer at the interface. Similar hindrance of oxygen mass transfer applies to waters from sewage plants (filtered raw water and treated water), making accurate design of aeration tanks difficult.

\section{Highlights}

- Gas-liquid mass transfer coefficients were found from two flow visualization methods

- Surfactants reduce mass transfer not only by retarding bubble rise velocities

- Surfactants beyond Critical Micelle Concentration congregate at gas-liquid interface

- This surfactant congregation causes further decline in interphase mass transfer

- Frössling correlation overestimates interphase mass transfer for wastewater

Keywords: Surfactants, Wastewater, Bubbles, PLIF, Mass transfer, Interface

\section{Introduction}

55 For wastewater treatment (e.g. in activated sludge or membrane bioreactors), a supply of dissolved oxygen, e.g. by injecting air bubbles, is required to ensure the availability of microorganisms able to degrade specific pollutants. The path of oxygen molecules in such processes is characterized by resistances at the gas/liquid interface (commonly represented as gas and liquid films), in the bulk liquid and on both sides of the liquid/microorganism interface (Garcia-Ochoa and Gomez, 2009). However, due to the low solubility of oxygen in aqueous solutions $\left(\mathrm{He}=4.05 \times 10^{9} \mathrm{~Pa}\right.$, He being the Henry's law constant of oxygen in water at $20^{\circ} \mathrm{C}$, Roustan, 2003), the main resistance to oxygen mass transfer is usually assumed to be located in a thin film of liquid surrounding the bubble and characterized by a liquid side mass transfer coefficient $\mathrm{k}_{\mathrm{L}}(\mathrm{m} / \mathrm{s})$. Since compressors required to inject air bubbles represent almost $70 \%$ of the total energy consumption of sewage plants, accurate determination of $\mathrm{k}_{\mathrm{L}}$ is 
of prime interest to avoid over- or under-estimating of the required oxygen supply to the process.

70 Several studies have focused on characterizing oxygen mass transfer in wastewater although most of these have been limited to the evaluation of the product $\mathrm{k}_{\mathrm{L}} \times \mathrm{a}$, considered to be the volumetric mass transfer coefficient with a the interfacial area $\left(\mathrm{m}^{2} / \mathrm{m}^{3}\right)$ (Redmond et al., 1983; Gillot et al., 2005; Hébrard et al., 2000; Rosso et al., 2006; Germain et al., 2007). The standardized dynamic method for measuring $k_{L} \times a$ in clean water is covered elsewhere (ASCE 1992). Indeed impacts on $k_{L} \times a$ of air flow rate, presence of suspended solids, biomass, antifoams, sludge age, bioreactor geometry, liquid viscosity, ion concentration, temperature, etc. have been investigated in detail over recent decades (e.g. Ju 1995, Gillot 2005, Rosso 2005, Germain 2006, Garcia 2009). The huge number of parameters which can influence $k_{L} \times a$ makes it difficult to predict the optimal oxygen supply to aerated processes. Moreover, these $\left(\mathrm{k}_{\mathrm{L}} \times \mathrm{a}\right)$-based approaches often make it impossible to determine the separate influence of specific parameters on $\mathrm{k}_{\mathrm{L}}$ and a. A relevant example to stress this point is the influence of surfactants.

85 Surfactants are ubiquitous in wastewaters due to the widespread use of soaps and detergents. Their ability to alter oxygen mass transfer has thus been massively considered in the literature (Bel Fdhila and Duineveld, 1996; Hébrard et al., 2000; Vasconcelos et al., 2002; Vasconcelos et al., 2003; Dai et al., 2004; Loubiere and Hébrard, 2004; Alves et al., 2005; Painmanakul et al., 2005; Sardeing et al., 2006; Rosso et al., 2006a; Rosso et al., 2006b; Hébrard et al., 2009; Jamnongwong et al., 2010) and can be summarized as follows:

- Surfactants are amphiphilic in nature. Near gas/liquid interfaces, their hydrophobic tails in the gas phase reduce gas renewal.

- Surfactants mainly accumulate at the bubble rear, in a stagnant cap due to shear at the surface.

- This accumulation at the bubble interface increases the bubble drag coefficient, thereby decreasing the bubble rise velocity.

- Bubble diameters decrease due to presence of surfactants, and this has a positively impact on the interfacial area a. 
- Liquid side mass transfer coefficients, $\mathrm{k}_{\mathrm{L}}$, are depressed by surfactants.

- With increasing surfactant concentrations, bubbles tend to behave like rigid particles, and the experimental $\mathrm{k}_{\mathrm{L}}$ values may then approach asymptotically the well-known correlation for solid spheres in steady state translation relative to a fluid (Frössling, 1938).

105 The reasons why surfactants depress $\mathrm{k}_{\mathrm{L}}$ are still controversial. Depending on the studies, this phenomenon has been attributed to a hydrodynamic alteration by lowering the renewal rates at the gas/liquid interface or to molecular obstruction hindering the diffusion of oxygen molecules to the bulk liquid. Surfactants thus have opposite effects, positively influencing the interfacial area while negatively affecting 110 the liquid side mass transfer coefficient. Techniques able to determine both $\mathrm{k}_{\mathrm{L}}$ and a are thus essential to evaluate the dominant effect on the global behaviour. In some studies (Painmanakul et al., 2005; Sardeing et al., 2006; Hébrard et al., 2009; Jamnongwong et al., 2010), the interfacial area is estimated by considering gas hold up and mean bubble diameter, allowing the liquid side mass transfer coefficient to be

115 evaluated. However, the global evaluation of $\mathrm{k}_{\mathrm{L}} \times \mathrm{a}$ (by oxygen probes for instance) remains a rough approach for understanding the governing mechanisms of mass transfer at the gas/liquid interface.

The purpose of this study is to consider methodologies developed by François et al. 120 (2011), Jimenez et al. (2012), Jimenez et al. (2013a) and Jimenez et al. (2013b) to elucidate the influence of surfactants on hydrodynamics and oxygen mass transfer in wastewater. One of these novel methodologies is based on a simplified configuration, with single oxygen bubbles of diameter $\sim 1 \mathrm{~mm}$ rising in a quiescent liquid. While this approach is far from bubble swarms encountered in aerated processes, surfactants act right at the gas/liquid interface, and thus at a very local scale, so that this simplified configuration facilitates interpretation beyond the mechanisms occurring in presence of surfactants in wastewaters. The second methodology evaluates oxygen diffusion through a planar oxygen/liquid interface in a Hele-Shaw cell. For both of these configurations, the Planar Laser Induced Fluorescence (PLIF) technique 130 provides accurate and local visualization and quantification of the transferred oxygen concentration fields. Evaluation of bubble diameter $\mathrm{d}_{\mathrm{eq}}$, aspect ratio $\chi$, rise velocity $\mathrm{U}_{\mathrm{b}}$, transferred oxygen flux $\mathrm{F}$, liquid side mass transfer coefficient $\mathrm{k}_{\mathrm{L}}$, diffusion 
coefficient D and oxygen solubility $\left[\mathrm{O}_{2}\right]^{*}$ are investigated in this paper to perform a complete mapping of hydrodynamics and mass transfer in demineralized water, demineralized water plus surfactants and wastewaters from a conventional sewage treatment plant (France,

\section{Materials and methods}

The PLIF technique refers to the absorption and emission of light, at different wavelengths, by a fluorescent dye incorporated in the liquid phase of interest. The excitation light can be generated by a monochromatic laser source whose emission

145 wavelength corresponds to the absorption spectrum of the dye. Part of this excitation light is absorbed by the dye, leading to an excited electronic state. The light that is reemitted by the dye to return to the fundamental state has a longer wavelength than the absorbed light (Jablonski, 1933; Crimaldi, 2008). This phenomenon is called fluorescence. This process can be inhibited by the presence of quenchers, substances

150 able to absorb (by collisions for instance) surplus energy accumulated by the dye. Oxygen molecules are known to be excellent quenchers (for specific fluorescent dyes) and have been utilized in several studies dealing with PLIF measurements (Jirka et al., 2004; Dani et al., 2007; Kück et al., 2010; François et al., 2011; Jimenez et al., 2012; Kück et al., 2012; Chen et al., 2013, Jimenez et al., 2013a; Jimenez et al., 2013b). 155 Since oxygen molecules inhibit dye fluorescence, their presence in a liquid phase can easily be tracked and quantified based on the Stern-Volmer correlation,

$$
\frac{\mathrm{I}_{\mathrm{O}}}{\mathrm{I}}=1+\mathrm{K}_{\mathrm{SV}}\left[\mathrm{O}_{2}\right]
$$

where $\left[\mathrm{O}_{2}\right]$ is the concentration of dissolved oxygen in the liquid phase $(\mathrm{mg} / \mathrm{L})$, I is 160 the fluorescence intensity , $\mathrm{I}_{0}$ the fluorescence intensity in the absence of oxygen and $\mathrm{K}_{\mathrm{SV}}$ the Stern-Volmer constant $(\mathrm{L} / \mathrm{mg})$. The parameters $\mathrm{I}_{0}$ and $\mathrm{K}_{\mathrm{Sv}}$ are experimentally determined by calibration $\mathrm{I}=\mathrm{f}\left(\left[\mathrm{O}_{2}\right]\right)$ as proposed in Figure 1. Fluorescence intensities are recorded after dye excitation in a liquid of known and uniform oxygen concentration, measured by oxygen microprobes (Luminescent Dissolved Oxygen 
165 Probe, Hach Lange). In a previous study, Jimenez et al. (2013b) demonstrated that fluorescence can be directly affected by the liquid phase composition. For instance, demineralized water to which small amounts of salt had been added experienced a in dye solubility and thus a decrease in fluorescence intensities. Such intensity decreases limit the accuracy of determining the corresponding oxygen concentration fields 170 (based on Equation (1)). Moreover, a decrease in dye solubility implies a higher contamination rate at the gas/liquid interface that could strongly affect the measured oxygen mass transfer. To overcome these difficulties, a new dye, Dichlorotris $(1,10-$ Phenanthroline) Ruthenium(II) hydrate (CAS: 207802-45-7, Sigma Aldrich, USA), is introduced in this study. This dye is directly soluble in aqueous phase, does not 175 significantly alter the liquid phase properties as indicated in Table 1 and presents constant calibration parameters $\left(\mathrm{I}_{0}\right.$ and $\mathrm{K}_{\mathrm{SV}}$ in Equation (1)) in the different liquids considered in this study (Figure 1).

Table 1. Physico-chemical characteristics of demineralized water in absence and 180 presence of $50 \mathrm{mg} / \mathrm{L}$ of fluorescent dye (Dichlorotris (1,10-Phenanthroline) Ruthenium(II) hydrate) at $20 \pm 1^{\circ} \mathrm{C} . \sigma_{L}, \varrho_{L}$ and $\mu_{L}$ are measured respectively with a tensiometer (Digidrop GBX 3S ${ }^{\circledR}$ ), a Ubbelhode viscometer (Schott Gerate Typ 501 03/Oc) and a pycnometer (Brand Duran).

\begin{tabular}{lccc}
\hline Liquid phase & $\begin{array}{c}\text { Surface tension } \\
\sigma_{\mathrm{L}}(\mathrm{mN} / \mathrm{m})\end{array}$ & $\begin{array}{c}\text { Liquid density } \\
\varrho_{\mathrm{L}}(\mathrm{kg} / \mathrm{m} 3)\end{array}$ & $\begin{array}{c}\text { Liquid viscosity } \\
\mu_{\mathrm{L}}(\mathrm{Pa} . \mathrm{s})\end{array}$ \\
\hline $\begin{array}{l}\text { Demineralized water } \\
\text { Demineralized water+50 }\end{array}$ & 73.7 & 995 & 0.001 \\
$\mathrm{mg} / \mathrm{L}$ of fluorescent dye & 73.3 & 995 & 0.001 \\
\hline
\end{tabular}



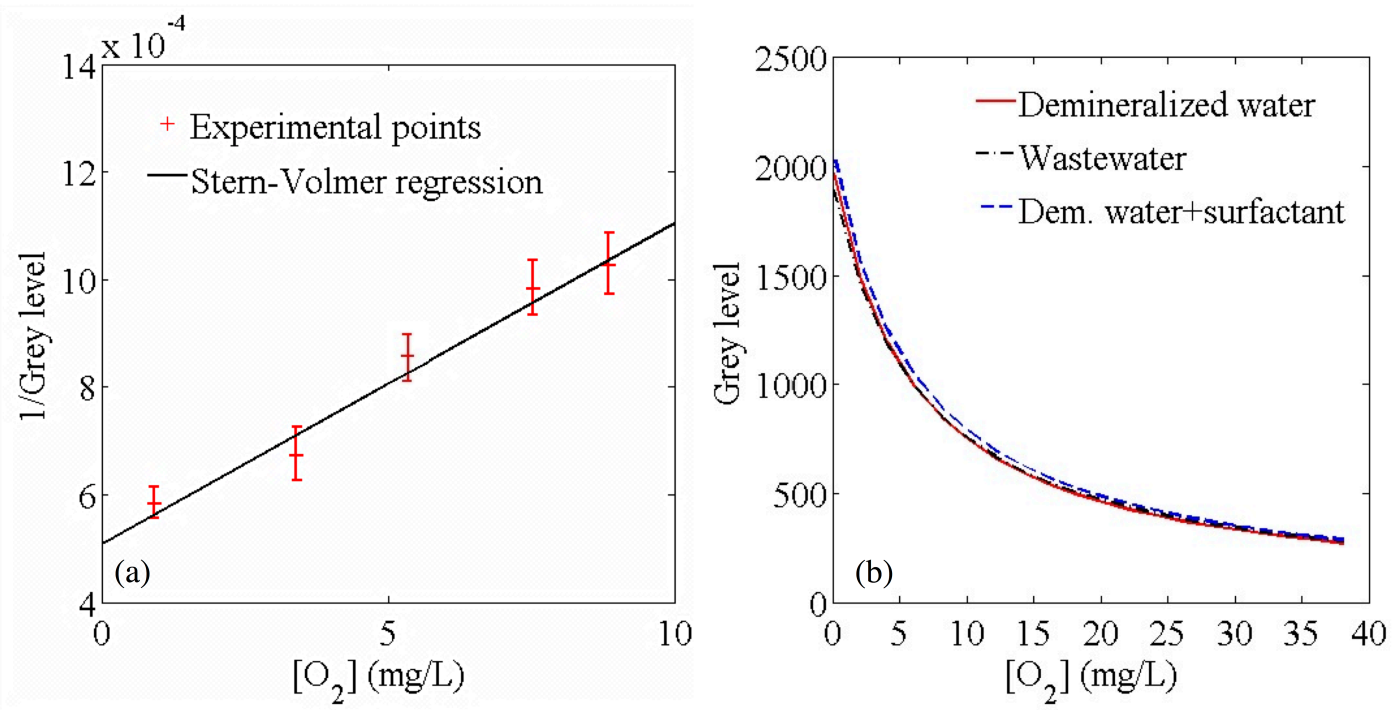

Figure 1. (a) Experimental fluorescence intensities recorded in water for different uniform oxygen concentrations measured by oxygen probes with Dichlorotris dye. Straight line: corresponding linear regression based on the Stern-Volmer correlation $\left(I_{0}=1969, K_{S V}=0.12 \mathrm{~L} / \mathrm{mg}\right)$. (b) Extrapolated calibration curves (straight line in the left part of Figure 1) based on the Stern-Volmer correlation with Dichlorotris dye in demineralized water, filtered wastewater and demineralized water containing a small amount of dish soap.

Since oxygen concentration fields are directly extrapolated from the Stern-Volmer calibration, $\mathrm{I}_{0}$ and $\mathrm{K}_{\mathrm{Sv}}$ are determined for each liquid studied and only assumed valid for one day. Based on the PLIF technique, two methodologie developed by François et al. (2011), Jimenez et al. (2012), Jimenez et al. (2013a) and Jimenez et al. (2013b) are used to evaluate the influence on oxygen mass transfer of surfactants and filtered waters extracted from sewage plants.

\section{(a) Bubble experiments}

205 The first technique (François et al., 2011; Jimenez et al., 2013b) aims to visualize released oxygen in the wake of small bubbles rising in a quiescent liquid (Figure 2). The optical device is composed of a laser (LaVision, Nd: Yag, $2 \times 200 \mathrm{~mJ}$ ) exciting at $532 \mathrm{~nm}$ and $10 \mathrm{~Hz}$ the fluorescent dye solubilized in the liquid of interest (Dichlorotris (1,10-Phenanthroline) Ruthenium(II), $50 \mathrm{mg} / \mathrm{L}$ ) along a horizontal plane. A CCD camera (LaVision, 12 bits, $1376 \times 1024$ pixels) is placed below the 
column and focuses along the laser sheet to record synchronously the fluorescence intensities. The corresponding spatial window is about $3 \times 4 \mathrm{~mm}^{2}$. A high-speed camera (APX, 8 bits, $1024 \times 1024$ pixels) placed on the column side allows the rising bubbles to be visualized and hence the determination of its diameter $\mathrm{d}_{\mathrm{eq}}$, aspect ratio $\chi$,

215 velocity $\mathrm{U}_{\mathrm{b}}$. The corresponding spatial window is $3 \times 3 \mathrm{~cm}^{2}$.

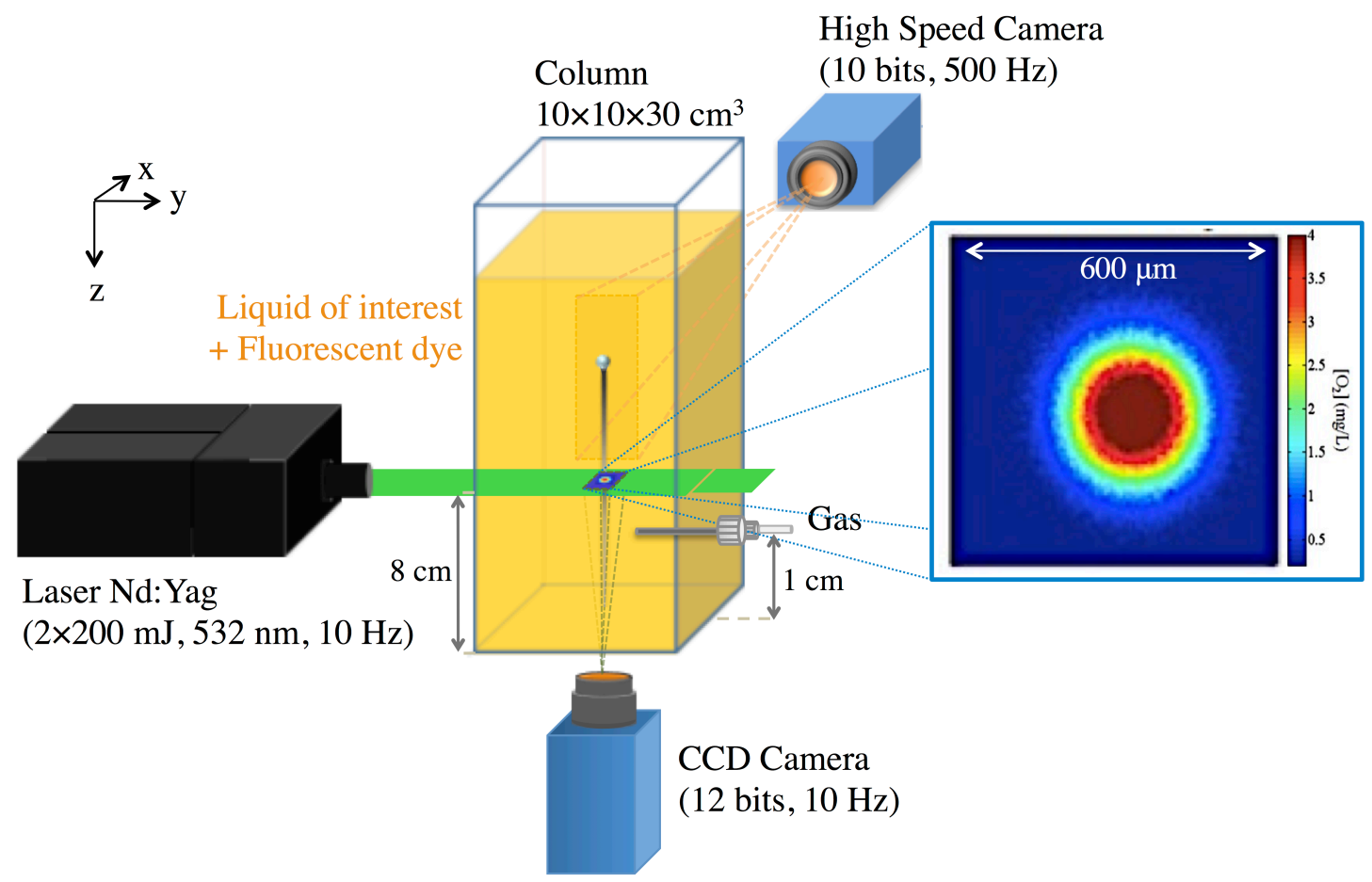

Figure 2. Experimental set-up for visualizing oxygen concentration fields in a bubble wake by PLIF and determining the bubble hydrodynamic characteristics by highspeed camera. Right part: example of experimental oxygen concentration field estimated in the wake of an oxygen bubble $\left(d_{e q}=1.23 \mathrm{~mm}, U_{b}=28.1 \mathrm{~cm} / \mathrm{s}, \chi=1.1\right)$ rising in demineralized water at about $300 d_{\text {eq }}$ from the bubble.

Images are recorded by the CCD camera (as portrayed at the right part of Figure 2) at 225 a frequency oh $10 \mathrm{~Hz}$, the upper limit for the optical device. This allows the evolution of the oxygen concentration field with time to be obtained. As noted by Jimenez et al. (2013b) the flux F (mg.s $\mathrm{s}^{-1}$ ) of oxygen transferred by the bubble is linked to the measured oxygen concentration field by

$$
\mathrm{F}=\mathrm{U}_{\mathrm{b}} \iint\left[\mathrm{O}_{2}\right] \mathrm{dxdy}
$$


with $\iint\left[\mathrm{O}_{2}\right] \mathrm{dxdy}$ the integration of the oxygen concentration field at a given time along the recording window. Note that Equation (2) is only valid when the hydrodynamic perturbation due to the bubble passage can be neglected (diffusion of released oxygen as the dominant transport phenomenon). By displaying the flux $\mathrm{F}$ for 235 all recorded images after the bubble passage as a function of time, $F$ first increases and reaches an asymptotic region once the dominance of diffusion is reached (see François et al. (2011) and Jimenez et al. (2013b) for further details). The flux F is then estimated by averaging values in this asymptotic region. The flux density $\mathbf{J}$ (mg.s${ }^{1} \cdot \mathrm{m}^{-2}$ ) can be deduced from the estimated flux $\mathrm{F}$ as

$$
\mathrm{J}=\frac{\mathrm{F}}{\mathrm{S}_{\mathrm{b}}}
$$

with $S_{b}$ the bubble surface being a function of the bubble diameter and aspect ratio, estimated by images recorded by a high-speed camera. The liquid side mass transfer coefficient $\mathrm{k}_{\mathrm{L}}\left(\mathrm{m} \cdot \mathrm{s}^{-1}\right)$ is then given by

$$
\mathrm{k}_{\mathrm{L}}=\frac{\mathrm{J}}{\left[\mathrm{O}_{2}\right]^{*}-\left[\mathrm{O}_{2}\right]_{0}}
$$

with $\left[\mathrm{O}_{2}\right]^{*}$ the oxygen solubility and $\left[\mathrm{O}_{2}\right]_{0}$ the oxygen concentration in the bulk liquid. Experimental $\mathrm{k}_{\mathrm{L}}$ values can classically be compared to two classical limiting cases: Higbie (1935) and Frössling (1938) equations characterizing bubbles with clean and 250 rigid surfaces, respectively.

$$
\begin{gathered}
\mathrm{k}_{\mathrm{L}_{\text {Higbie }}}=\frac{\mathrm{D}}{\mathrm{d}_{\mathrm{eq}}}\left(1.13 \mathrm{Re}^{0.5} \mathrm{Sc}^{0.5}\right) \\
\mathrm{k}_{\mathrm{L}_{\text {Frössling }}}=\frac{\mathrm{D}}{\mathrm{d}_{\mathrm{eq}}}\left(2+0.66 \mathrm{Re}^{0.5} \mathrm{Sc}^{0.33}\right)
\end{gathered}
$$


255 with $\mathrm{D}$ the oxygen diffusion coefficient $\left(\mathrm{m}^{2} \cdot \mathrm{s}^{-1}\right), \mathrm{d}_{\mathrm{eq}}$ the equivalent bubble diameter $(\mathrm{m}), \operatorname{Re}\left(=\mathrm{d}_{\mathrm{eq}} \times \mathrm{U}_{\mathrm{b}} \times \mathrm{Q}_{\mathrm{L}} / \mu_{\mathrm{L}}\right)$ the Reynolds number and Sc $\left(=\mu_{\mathrm{L}} / \mathrm{DQ}_{\mathrm{L}}\right)$ the Schmidt number. To evaluate the contamination rate of the rising bubble, contamination angles are also considered based on the approach of Sadhal and Johnson (1983):

$$
\frac{C_{D}-C_{D}^{m}}{C_{D}^{i m}-C_{D}^{m}}=\frac{1}{2 \pi}\left(2\left(\pi-\theta_{c a p}\right)+\sin \theta_{c a p}+\sin 2 \theta_{c a p}-\frac{1}{3} \sin 3 \theta_{c a p}\right)
$$

260

with $\theta_{\text {cap }}$ the contamination angle from the front, $C_{D}, C_{D}{ }^{m}$ and $C_{D}{ }^{i m}$ are drag coefficients corresponding to the experimental bubble and bubbles characterized by mobile and immobile surfaces respectively. $C_{D}{ }^{m}$ and $C_{D}{ }^{i m}$ are approached by correlations proposed by Schiller and Naumann (1933) and Mei et al. (1994), 265 respectively.

\section{(b) Hele-Shaw cell measurements}

Based on Equations (5) and (6), the liquid side mass transfer coefficient is directly related to the oxygen diffusion coefficient D. Since diffusion coefficients in the literature differ drastically for oxygen-water systems at $20^{\circ} \mathrm{C}$ (values ranging from 0.7 to $2.5 \times 10^{-9} \mathrm{~m}^{2} \cdot \mathrm{s}^{-1}$ ), the methodology developed by Jimenez et al. (2012) and Jimenez et al. (2013a) using the PLIF technique is also investigated. Oxygen concentration fields were also visualized near a planar oxygen/liquid interface in a thin Hele-Shaw cell filled with about $10 \mathrm{~mL}$ of deoxygenated liquid with a $10 \mathrm{~L} / \mathrm{h}$ pure oxygen flow rate passes over the interface (Figure 3) at a velocity too low to cause ripples on the surface (average gas velocity in the Hele-Shaw cell $0.07 \mathrm{~m} / \mathrm{s}$ ). The optical device is similar to the one presented previously, with a recording spatial window of about $5 \times 6$ $\mathrm{mm}^{2}$. 


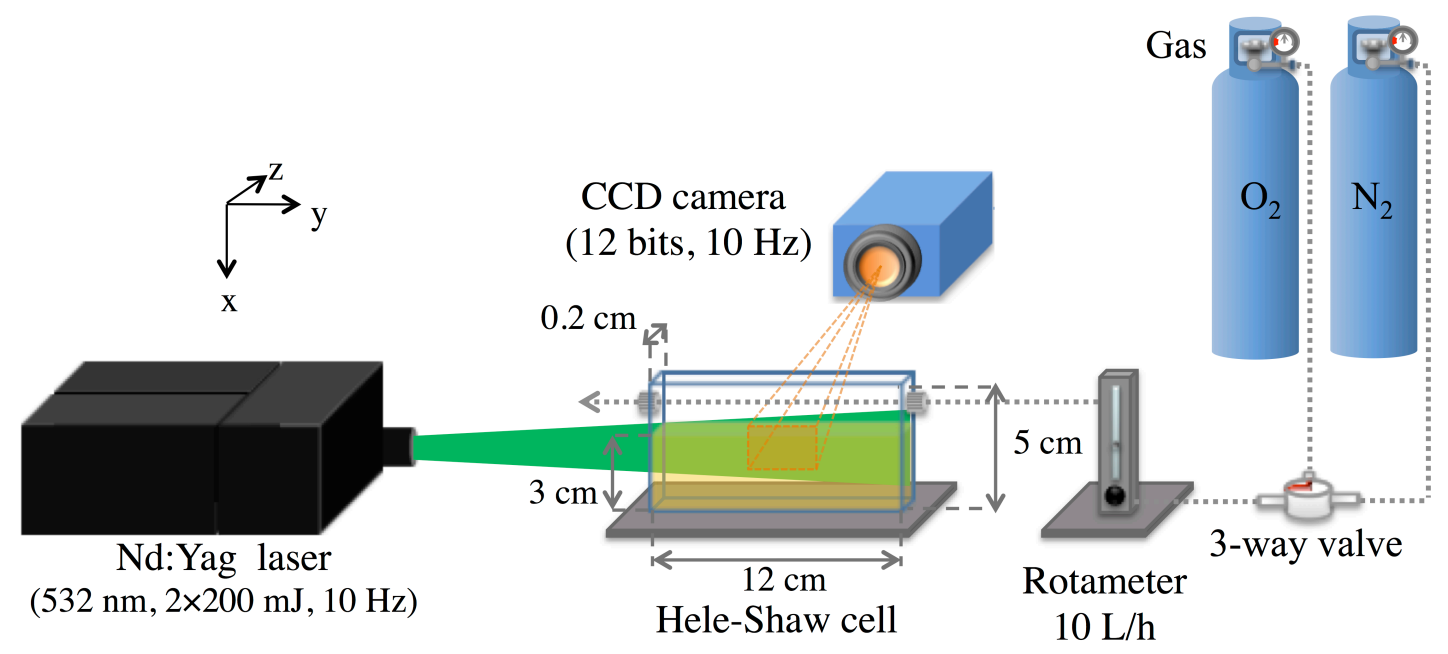

Figure 3. Experimental set-up for visualizing oxygen concentration fields near a planar gas/liquid interface by means of PLIF technique.

Figure 4 presents an example of images recorded by considering this technique in an oxygen-water plus surfactant solution. In the top region of thickness $0.7 \mathrm{~mm}$, there is no fluorescence since this corresponds to the gas phase. Then, for $0.7 \leq x^{\prime} \leq 1.1 \mathrm{~mm}$, a high intensity (white area) is visualized due to the laser reflection at the gas-liquid 290 interface. For x'> $1.1 \mathrm{~mm}$, fluorescence intensities in the liquid phase are recorded. At the beginning (up to $\mathrm{t}=30 \mathrm{~s}$ ), the liquid phase is almost deoxygenated and characterized by strong fluorescence intensities. Due to inhibition of fluorescence in the presence of oxygen molecules, the fluorescence intensity in the liquid darkens with time as oxygen diffuses into the liquid. 

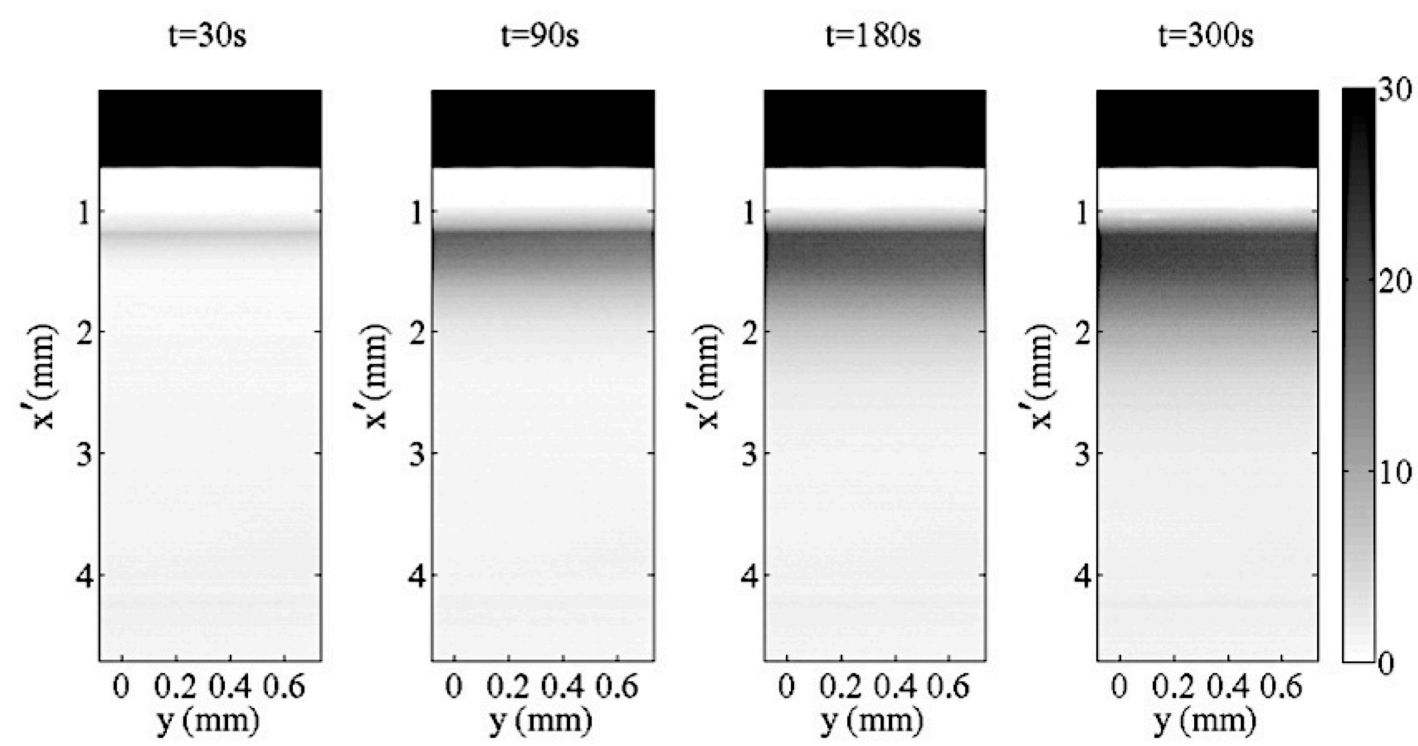

Figure 4. Example of recorded images using PLIF technique near a planar oxygen/water + surfactant $(0.008 \mathrm{~mL} / \mathrm{L}$ of dish soap) interface to visualize the diffusion of oxygen at different times. Colour bar represents oxygen concentrations in $\mathrm{mg} / \mathrm{L}$.

This Hele-Shaw cell configuration allows the problem to be reduced to two dimensions (contribution along the $\mathrm{z}$-axis neglected). Under well-defined gas flow rate and according to Jimenez et al. (2013a), there is no significant convection in the $y$-direction in the recording window and the transfer of oxygen in the liquid phase is a planar diffusive in the $\mathrm{x}$-direction (Figure 4). Note that Particle Image Velocimetry measurements have been conducted to verify this assumption, with similar conclusions as in Jimenez et al. (2013a). The duration of experiments (few minutes) being short compared with the diffusion characteristic time $\left(\mathrm{t} \approx \mathrm{L}^{2} / \mathrm{D}=75 \mathrm{~min}\right.$, with $\mathrm{L}$ a characteristic length $(3 \mathrm{~mm}$ for instance, corresponding to the size of the recorded image in the liquid phase) and $\mathrm{D}$ the diffusion coefficient $\approx 2 \times 10^{-9} \mathrm{~m}^{2} / \mathrm{s}$ for an oxygen/water system at $20^{\circ} \mathrm{C}$ ), the analytical solution of Fick's law for a semi infinite media (Fick 1855, Crank 1975) is

$$
\frac{\left[\mathrm{O}_{2}\right](\mathrm{x}, \mathrm{t})-\left[\mathrm{O}_{2}\right]_{0}}{\left[\mathrm{O}_{2}\right]^{*}-\left[\mathrm{O}_{2}\right]_{0}}=1-\operatorname{erf}\left(\frac{\mathrm{x}}{2 \sqrt{\mathrm{Dt}}}\right),
$$

315 with $\mathrm{x}$ the distance from the gas/liquid interface $(\mathrm{m})$ and $\mathrm{t}$ the time since the beginning of the diffusive process (s). Since oxygen concentrations are constant for a fixed value of $\mathrm{x}$ (Figure 4), they are averaged along the y-axis to obtain an averaged oxygen 
concentration profile as a function of the distance from the interface and as a function of time. Examples of experimental profiles are plotted in Figure 5.

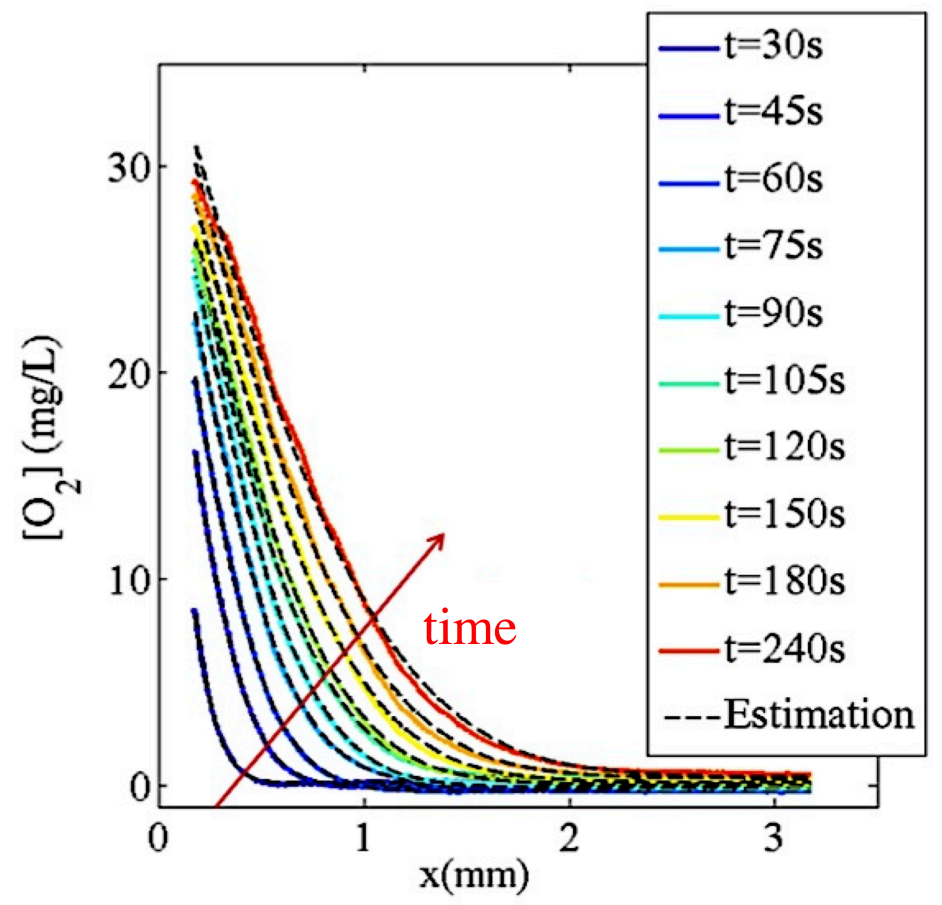

Figure 5. Experimental oxygen concentration profile as a function of distance from oxygen/water interface at $19 \pm 1^{\circ} \mathrm{C}$ compared to analytical solution to the Fick's law in a semi-infinite medium.

325 The diffusion coefficient is then estimated by minimization of the function

$$
\sum_{x} \sum_{t}\left\|\left[\mathrm{O}_{2}\right](\mathrm{x}, \mathrm{t})_{\exp }-\left[\mathrm{O}_{2}\right](\mathrm{x}, \mathrm{t})_{\text {analytic }}\right\|^{2} / 2,
$$

with $\left[\mathrm{O}_{2}\right](\mathrm{x}, \mathrm{t})_{\exp }$ the experimental oxygen concentration and $\left[\mathrm{O}_{2}\right](\mathrm{x}, \mathrm{t})_{\text {analytic }}$ the concentration deduced from the analytical solution (Equation 8). This minimization is performed by a Markov Chain Monte Carlo method (MCMC), a statistical method more robust than classical gradient-based solvers. Further information can be found in (Robert and Casella, 1999). The experimental oxygen concentration profile $\left[\mathrm{O}_{2}\right](\mathrm{x}, \mathrm{t})_{\exp }$ and the corresponding distance from the interface $\mathrm{x}$ and time $\mathrm{t}$ are the required parameters for the MCMC resolution. After minimization of the function in (9), the diffusion coefficient $\mathrm{D}$, oxygen saturation concentration $\left[\mathrm{O}_{2}\right]^{*}$ and uncertainties on the position of the interface $\mathrm{x}=0$ and time $\mathrm{t}=0$ are estimated. Table 2 presents MCMC 
results corresponding to the experimental oxygen profile in Figure 5 for an oxygenwater system at $20^{\circ} \mathrm{C}$.

Table 2. Estimated oxygen solubility [O2]*, diffusion coefficient D, uncertainties $\delta x$ 340 and $\delta t$ on the experimental estimates of $x=0$ and $t=0$ for an oxygen water system at $20 \pm 1{ }^{\circ} \mathrm{C}$ by the MCMC method.

\begin{tabular}{ccccc}
\hline Estimated parameter & {$\left[\mathrm{O}_{2}\right]^{*}(\mathrm{mg} / \mathrm{L})$} & $\mathrm{D} \times 10^{9}\left(\mathrm{~m}^{2} / \mathrm{s}\right)$ & $\delta \mathrm{x}(\mu \mathrm{m})$ & $\delta \mathrm{t}(\mathrm{s})$ \\
\hline Estimated value & $39.0 \pm 0.3$ & $1.90 \pm 0.01$ & $1.0 \pm 0.5$ & $20.8 \pm 0.3$ \\
\hline
\end{tabular}

345 Estimated values of solubility and diffusion coefficient are in good agreement (relative errors less than 10\%) with values usually encountered in the literature (Scheibel, 1954; Wilke and Chang, 1955; Roustan, 2003; Jamnongwong et al., 2010). For an oxygen-water system, the experimental uncertainty of the $\mathrm{x}=0$ position (referring to the methodology proposed by Jimenez 2013a) is negligible compared with the $21 \mathrm{~s}$ shift for $\mathrm{t}=0$. The time started experimentally when the 3 -way valve was switched to oxygen. However, this neglects the required time for the gas to reach the Hele-Shaw cell, which can explain this large $\delta t$ value.

\section{(c) Liquids investigated}

To summarize, the first technique allows the oxygen mass transfer to be visualized and quantified in the wake of small oxygen bubbles rising in a quiescent liquid. The bubble diameter $\mathrm{d}_{\mathrm{eq}}$, aspect ratio $\chi$, rise velocity $\mathrm{U}_{\mathrm{b}}$, contamination angle $\theta_{\text {cap }}$ as well as oxygen transfer flux $\mathrm{F}$, flux density $\mathrm{J}$ and liquid-side mass transfer coefficient $\mathrm{k}_{\mathrm{L}}$ are all determined. The second technique determines oxygen concentration fields near a planar oxygen/liquid interface under controlled hydrodynamic conditions in a HeleShaw cell. This diffusive process leads to the estimation of the oxygen solubility $\left[\mathrm{O}_{2}\right]^{*}$ and diffusion coefficient $\mathrm{D}$.

All of these parameters were measured for demineralized water, water plus surfactants

365 and water extracted from a sewage plant. Surfactants tested were dish soap (0.004 $\mathrm{mL} / \mathrm{L}$ and $0.008 \mathrm{~mL} / \mathrm{L}$, PAIC Citron $\left.{ }^{\circledR}\right)$ and Caprylate monoglyceride $\mathrm{C}_{11} \mathrm{H}_{20} \mathrm{O}_{5}(0.02$ 
and $0.22 \mathrm{~g} / \mathrm{L}$ ). Wastewaters were extracted from a sewage plant working with activated sludge (Saint-Vrain, France, with an average wastewater flow rate of wastewaters of $2853 \mathrm{~m}^{3} /$ day). Raw wastewater and treated water were investigated in this study after filtration with membranes of $0.2-\mu \mathrm{m}$ and $2-\mu \mathrm{m}$ pore diameter respectively. The relevant physico-chemical properties of these liquids, each containing $50 \mathrm{mg} / \mathrm{L}$ of fluorescent dye are presented in Table 3.

Table 3. Measured liquid surface tension $\sigma_{L}$, density $\varrho_{L}$, viscosity $\mu_{L}, p H$ and conductivity $\lambda$ for demineralized water and various aqueous solutions tested at atmospheric pressure and $19 \pm 2{ }^{\circ} \mathrm{C}$. All these liquids contained $50 \mathrm{mg} / \mathrm{L}$ of fluorescent dye.

\begin{tabular}{cccccc}
\hline $\begin{array}{c}\text { Liquid phase } \\
+50 \mathrm{mg} / \mathrm{L} \text { of dye }\end{array}$ & $\begin{array}{c}\sigma_{\mathrm{L}} \\
(\mathrm{mN} / \mathrm{m})\end{array}$ & $\begin{array}{c}\mathrm{Q}_{\mathrm{L}} \\
(\mathrm{kg} / \mathrm{m} 3)\end{array}$ & $\begin{array}{c}\mu_{\mathrm{L}} \\
(\mathrm{mPa} . \mathrm{s})\end{array}$ & $\begin{array}{c}\mathrm{pH} \\
(\mu \mathrm{S} / \mathrm{cm})\end{array}$ \\
\hline Demineralized water & 73.3 & 995 & 1.0 & 6.2 & 25 \\
\hline$+0.004 \mathrm{~mL} / \mathrm{L}$ dish soap & 58.6 & - & 1.0 & 6.3 & 17 \\
$+0.008 \mathrm{~mL} / \mathrm{L}$ dish soap & 33.3 & - & 1.0 & 6.5 & 18 \\
\hline$+0.02 \mathrm{~g} / \mathrm{L} \mathrm{C}_{11} \mathrm{H}_{20} \mathrm{O}_{5}$ & 35.4 & 997 & 1.0 & 6.0 & 17 \\
$+0.22 \mathrm{~g} / \mathrm{L} \mathrm{C}_{11} \mathrm{H}_{20} \mathrm{O}_{5}$ & 33.3 & 998 & 1.0 & 6.1 & 16 \\
\hline Treated water & 69.3 & 998 & 1.0 & 7.9 & 1324 \\
Wastewater & 44.1 & 997 & 1.0 & 8.5 & 1266 \\
\hline
\end{tabular}

Table 3 shows that the presence of surfactants strongly decreases the liquid surface tension. Both caprylate monoglyceride cases are above the critical micelle concentration $(\mathrm{CMC}=0.013 \mathrm{~g} / \mathrm{L}$, Zhang et al., 2003). Discrepancies in measured surface tensions are probably related to the tensiometer accuracy $( \pm 1 \mathrm{mN} / \mathrm{m})$. As mentioned previously, surfactants are used daily and thus are largely present in sewage plants; as deduced from its measured surface tension.

\section{Experimental results}


Table 4 presents hydrodynamic results for isolated oxygen bubbles in the different liquids of interest whose properties appear in Table 3.

Table 4. Measured bubble diameter, aspect ratio, bubble rise velocity and contamination angle based on stagnant-cap approach for single oxygen bubbles in 395 different aqueous liquids including wastewater extracted from a sewage plant. \pm values correspond to repeatability errors estimated for at least five bubbles for each liquid.

\begin{tabular}{c|cccc}
\hline $\begin{array}{c}\text { Liquid phase } \\
+50 \mathrm{mg} / \mathrm{L} \text { of dye }\end{array}$ & $\begin{array}{c}\mathrm{d}_{\text {eq }} \\
(\mathrm{mm})\end{array}$ & $\begin{array}{c}\mathrm{U}_{\mathrm{b}} \\
(\mathrm{cm} / \mathrm{s})\end{array}$ & $\begin{array}{c}\theta_{\text {cap }} \\
\left({ }^{\circ}\right)\end{array}$ \\
\hline Demineralized water & $1.23 \pm 0.03$ & $1.12 \pm 0.02$ & $28.1 \pm 0.5$ & 136.3 \\
\hline$+0.004 \mathrm{~mL} / \mathrm{L}$ dish soap & $1.22 \pm 0.00$ & $1.02 \pm 0.00$ & $16.7 \pm 0.1$ & 98.0 \\
$+0.008 \mathrm{~mL} / \mathrm{L}$ dish soap & $1.22 \pm 0.00$ & $1.01 \pm 0.00$ & $13.6 \pm 0.1$ & 46.7 \\
\hline$+0.02 \mathrm{~g} / \mathrm{L} \mathrm{C}_{11} \mathrm{H}_{20} \mathrm{O}_{5}$ & $1.21 \pm 0.01$ & $1.01 \pm 0.02$ & $12.9 \pm 0.1$ & 0.0 \\
$+0.22 \mathrm{~g} / \mathrm{L} \mathrm{C}_{11} \mathrm{H}_{20} \mathrm{O}_{5}$ & $1.19 \pm 0.00$ & $1.02 \pm 0.01$ & $12.7 \pm 0.1$ & 0.0 \\
\hline Treated water & $1.23 \pm 0.01$ & $1.03 \pm 0.00$ & $20.6 \pm 0.1$ & 116.4 \\
Wastewater & $1.19 \pm 0.00$ & $1.01 \pm 0.00$ & $12.6 \pm 0.1$ & 0.0 \\
\hline
\end{tabular}

400 As observed in the literature (e.g. Clift et al., 1978; Alves et al., 2005), bubble rise velocities are strongly altered in presence of surfactants as a direct consequence of larger contamination angles. Fully contaminated bubbles are obtained for caprylate monoglyceride and filtered wastewaters. Unfortunately, it was impossible to perform experiments with higher concentrations of dish soap due to the presence of foam.

Volume-equivalent bubble diameters were similar for all the cases tested, although there was some variation in shape with aspect ratios approaching 1, corresponding to a spherical shape, in the presence of surfactants as indicated in Figure 6. Note that the contamination angle for demineralized water $\left(136^{\circ}\right)$ differs significantly from the $410180^{\circ}$ value characterizing a clean surface. This reflects the stringent measures needed to achieve surfactant fee conditions (Clift et al., 1978). The presence of the fluorescent may itself have contributed to bubble contamination. 

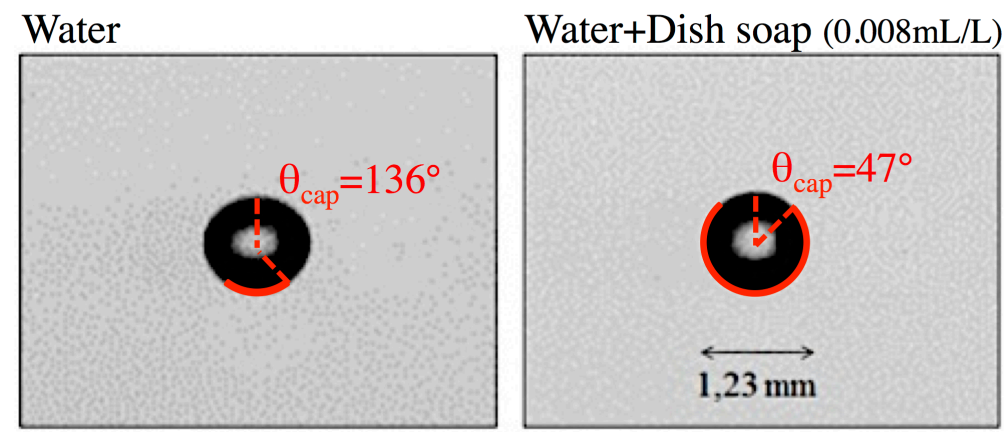

415 Figure 6. Visualization of oxygen single bubbles in demineralized water $\left(d_{e q}=1.23\right.$ $\mathrm{mm}, \chi=1.1, U_{b}=28.1 \mathrm{~cm} / \mathrm{s}$ ) and demineralized water $+0.008 \mathrm{~mL} / \mathrm{L}$ of dish soap $\left(d_{e q}=1.22 \mathrm{~mm}, \chi=1.0, U_{b}=13.6 \mathrm{~cm} / \mathrm{s}\right)$. Contact angles are based on the stagnant cap model.

420 There were substantial differences in the oxygen released in the wake of these bubbles,based on the PLIF technique. Figures 7 and 8 display oxygen concentration fields observed in the wake of bubbles, viewed horizontally (perpendicular to the bubble ascension, see Figure 2). Distances are deduced from the time elapsed between the bubble passing through the laser sheet and the corresponding recorded image, the 425 bubble rise velocity $\mathrm{U}_{\mathrm{b}}$ being known. Bubbles being almost spherical for all cases tested, the visualized oxygen concentration fields were always close to circular, growing with time due to diffusion. However, the higher the surface tension and the contamination angle, the weaker the oxygen concentration field in the bubble wake. For instance, in demineralized water with $0.008 \mathrm{~mL} / \mathrm{L}$ of dish soap, released oxygen is 430 hardly visible (oxygen concentrations less than $1 \mathrm{mg} / \mathrm{L}$ ). Similar conclusions can be obtained from the images recorded with bubbles in wastewater and treated water (Figure 8) even though a weaker depression in the oxygen concentration field is observed. 


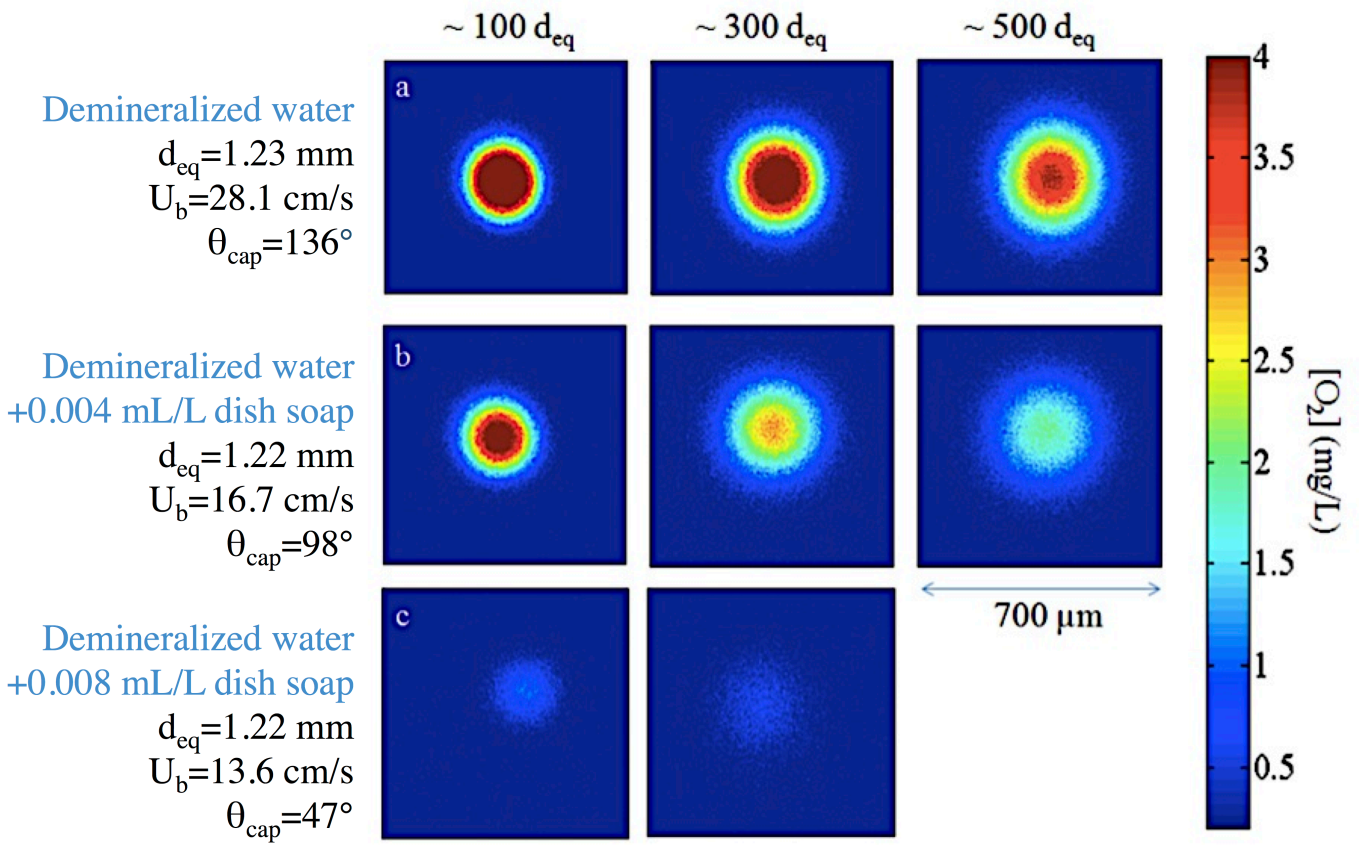

Figure 7. Oxygen concentration fields (expressed in $\mathrm{mg} / \mathrm{L}$ ) estimated by PLIF 440 technique for single rising oxygen bubbles in demineralized water, demineralized water $+0.004 \mathrm{~mL} / \mathrm{L}$ of dish soap and demineralized water $+0.008 \mathrm{~mL} / \mathrm{L}$ of dish soap at different distances from the bubble. Hydrodynamic characteristics of the bubbles are proposed at the left. 


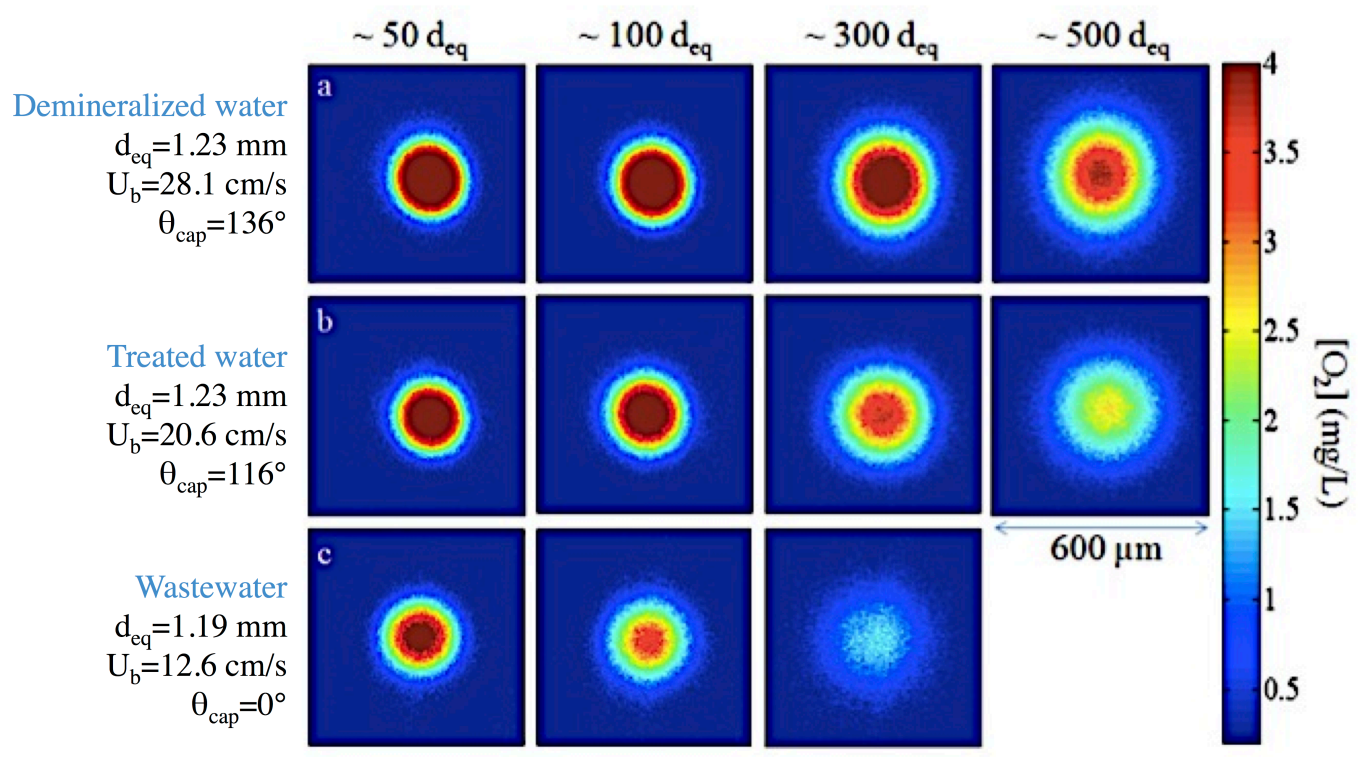

Figure 8. Oxygen concentration fields (expressed in $\mathrm{mg} / \mathrm{L}$ ) estimated by PLIF

technique for single rising oxygen bubbles in demineralized water, filtered treated water and wastewater from a sewage plant based on activated sludge treatment at different distances to the bubble. Hydrodynamic characteristics of the bubbles are provided at the left.

455 As a direct consequence of the reduction in released oxygen, parameters characterizing the mass transfer are affected also. Table 5 presents the corresponding $\iint\left[\mathrm{O}_{2}\right] d x d y$ integral, flux and flux densities estimated from Equations (2) and (3).

Table 5. Measured integral $\int\left[\mathrm{O}_{2}\right] d x d y$, transferred oxygen flux $\mathrm{F}$ and flux density based on equations (2) and (3) and images recorded with the PLIF for isolated oxygen bubbles in liquids whose properties are presented in Table 3.. \pm values correspond to repeatability error estimated at least five bubbles for each liquid of interest. 


\begin{tabular}{cccc}
\hline $\begin{array}{c}\text { Liquid phase } \\
+50 \mathrm{mg} / \mathrm{L} \text { of dye }\end{array}$ & $\begin{array}{c}\text { Integral } \\
\times 10^{5}(\mathrm{mg} / \mathrm{m})\end{array}$ & $\begin{array}{c}\text { Flux F } \\
\times 10^{6}(\mathrm{mg} / \mathrm{s})\end{array}$ & $\begin{array}{c}\text { Flux density J } \\
\left(\mathrm{mg} . \mathrm{m}^{-2} \cdot \mathrm{s}^{-1}\right)\end{array}$ \\
\hline Demineralized water & $27 \pm 3$ & $73 \pm 5$ & $15.4 \pm 0.9$ \\
\hline$+0.004 \mathrm{~mL} / \mathrm{L}$ dish soap & $17 \pm 1$ & $29 \pm 1$ & $6.3 \pm 1.0$ \\
$+0.008 \mathrm{~mL} / \mathrm{L}$ dish soap & $4 \pm 1$ & $5 \pm 1$ & $1.0 \pm 0.5$ \\
\hline$+0.02 \mathrm{~g} / \mathrm{L} \mathrm{C}_{11} \mathrm{H}_{20} \mathrm{O}_{5}$ & $8 \pm 1$ & $11 \pm 1$ & $2.3 \pm 0.5$ \\
$+0.22 \mathrm{~g} / \mathrm{L} \mathrm{C} \mathrm{H}_{11} \mathrm{H}_{20}$ & $3 \pm 1$ & $4 \pm 1$ & $0.7 \pm 0.2$ \\
\hline Treated water & $21 \pm 1$ & $43 \pm 2$ & $9.0 \pm 0.5$ \\
Wastewater & $12 \pm 1$ & $15 \pm 2$ & $3.4 \pm 0.1$ \\
\hline
\end{tabular}

For low liquid surface tensions, the integral term is markedly less than for demineralized water. Since the bubble rise velocity tends to decrease also, strong 480 diminutions in oxygen transferred flux and flux densities are observed. Table 5 shows the impact of the contamination angle on the oxygen mass transfer. For both caprylate monoglyceride cases (concentrations $>$ CMC), bubbles present a fully contaminated surface $\left(\theta_{\text {cap }}=0^{\circ}\right)$, with their rising velocities reaching a constant value regardless of the surfactant concentration. However, the integral, flux and flux densities in Table 4 continue to decline drastically for higher surfactant concentration. This clearly indicates the presence of an interfacial phenomenon hindering oxygen mass transfer beyond the impact on the rising velocity and Reynolds number. Based on the Higbie and Frössling equations (Equations (5) and (6)), another parameter apart from the Reynolds number impacting the $\mathrm{k}_{\mathrm{L}}$ value could be the bulk diffusion coefficient, $\mathrm{D}$.

490 To test this hypothesis, oxygen diffusion coefficients and solubilities are provided in Table 6 based on measurements in the Hele-Shaw cell through a planar oxygen/liquid interface. 
Table 6. Measured oxygen diffusion coefficient $\mathrm{D}$ and solubility $\left[\mathrm{O}_{2}\right]^{*}$ based on equation (9) and images recorded with the PLIF technique through a planar oxygen/liquid interface for different liquids. \pm values correspond to repeatability error estimated from at least three measurements for each liquid of interest.

\begin{tabular}{ccc}
\hline $\begin{array}{c}\text { Liquid phase } \\
+50 \mathrm{mg} / \mathrm{L} \text { of dye }\end{array}$ & $\begin{array}{c}\mathrm{D} \\
\times 10^{9}\left(\mathrm{~m}^{2} / \mathrm{s}\right)\end{array}$ & $\begin{array}{c}{\left[\mathrm{O}_{2}\right]^{*}} \\
(\mathrm{mg} / \mathrm{L})\end{array}$ \\
\hline Demineralized water & $1.90 \pm 0.1$ & $39.0 \pm 0.2$ \\
\hline$+0.004 \mathrm{~mL} / \mathrm{L}$ dish soap & $1.60 \pm 0.10$ & $49.0 \pm 1.0$ \\
$+0.008 \mathrm{~mL} / \mathrm{L}$ dish soap & $1.70 \pm 0.10$ & $31.0 \pm 1.0$ \\
\hline$+0.02 \mathrm{~g} / \mathrm{L} \mathrm{C}_{11} \mathrm{H}_{20} \mathrm{O}_{5}$ & - & - \\
$+0.22 \mathrm{~g} / \mathrm{L} \mathrm{C}_{11} \mathrm{H}_{20} \mathrm{O}_{5}$ & - & - \\
\hline Treated water & $2.02 \pm 0.10$ & $42.0 \pm 1.0$ \\
Wastewater & $2.03 \pm 0.20$ & $46.0 \pm 2.0$ \\
\hline
\end{tabular}

500

Surprisingly, experimental diffusion coefficients in the presence of surfactants and in waters extracted from sewage plant are quite similar to that of an oxygen-water system, although there was an appreciable decrease in the presence of dish soap. No tendencies can be deduced from the estimated saturation concentrations, extrapolated 505 from experimental profiles (such as Figure 5) at the gas/liquid interface $(x=0)$. However due to a thicker meniscus at the gas/liquid interface in the presence of surfactants, a higher reflection area appears in the recorded images. As is clearly visible in Figure 3, a $0.5 \mathrm{~mm}$ area of high reflection, characterized by the white zone at about $x^{\prime} \approx 1 \mathrm{~mm}$, hinders accurate location of the gas/liquid interface and thus 510 estimation of oxygen solubility. Note that for an oxygen-water system, this reflection zone is less than 0.1 in height facilitating estimation of the oxygen solubility. Nevertheless, oxygen concentrations measured by probes in these liquids saturated with oxygen are insensitive to the presence of surfactants. Our experimental results from the Hele-Shaw cell indicate that there is no significant difference between 515 demineralized water, demineralized water and surfactant and waters extracted from sewage plant in term of diffusion coefficient and solubility. 
This result means that, for the cases dealing with caprylate monoglyceryde, there is negligible difference in the Schmidt and Reynolds numbers for the tested concentrations. Liquid-side mass transfer coefficients estimated by the Frössling correlation are thus similar for these two concentrations. However, as mentioned above, the higher the surfactant concentration, the lower the experimental oxygen transferred flux, flux density and $\mathrm{k}_{\mathrm{L}}$. Table 7 presents experimental liquid-side mass transfer coefficients estimated with:

- Experimental values, $\mathrm{k}_{\mathrm{L}}$ exp, based on experimental oxygen solubilities (Table 6) and on equation (4).

- Values labelled $\mathrm{k}_{\mathrm{L}}$ exp' based on experimental solubility obtained in demineralized water (since no major difference in terms of solubility was measured by oxygen probes) and equation (4).

- Values labelled $\mathrm{k}_{\mathrm{L}}$ Frössling from the Frössling correlation (Equation 6) applied with estimated diffusion coefficients (from Table 6).

Table 7. Comparison of experimental liquid-side mass transfer coefficients for different liquid media with $\left(k_{L \text { exp }}\right)$ experimental oxygen solubility presented in Table 5 or with the solubility of oxygen in water $\left(k_{\text {Lexp }}{ }^{\prime}\right)$ and with liquid-side mass transfer coefficient estimated with the equation of Frössling (1938).

\begin{tabular}{c|cccc}
\hline $\begin{array}{c}\text { Liquid phase } \\
+50 \mathrm{mg} / \mathrm{L} \text { of dye }\end{array}$ & $\begin{array}{c}\mathrm{k}_{\mathrm{L}} \exp \\
\times 10^{4}(\mathrm{~m} / \mathrm{s})\end{array}$ & $\begin{array}{c}\mathrm{k}_{\mathrm{L}} \text { exp’ } \\
\times 10^{4}(\mathrm{~m} / \mathrm{s})\end{array}$ & $\begin{array}{c}\mathrm{k}_{\mathrm{L}} \text { Frössling } \\
\times 10^{4}(\mathrm{~m} / \mathrm{s})\end{array}$ & $\begin{array}{c}\theta_{\text {cap }} \\
\left.{ }^{\circ}\right)\end{array}$ \\
\hline Demineralized water & 3.95 & 3.95 & 1.53 & 136.3 \\
\hline$+0.004 \mathrm{~mL} / \mathrm{L}$ dish soap & 1.29 & 1.62 & 1.06 & 98.0 \\
$+0.008 \mathrm{~mL} / \mathrm{L}$ dish soap & 0.32 & 0.26 & 0.99 & 46.7 \\
\hline$+0.02 \mathrm{~g} / \mathrm{L} \mathrm{C}_{11} \mathrm{H}_{20} \mathrm{O}_{5}$ & 0.48 & 0.59 & 1.05 & 0.0 \\
$+0.22 \mathrm{~g} / \mathrm{L} \mathrm{C} \mathrm{C}_{11} \mathrm{H}_{20}$ & 0.16 & 0.18 & 1.06 & 0.0 \\
\hline Treated water & 2.14 & 2.31 & 1.37 & 116.4 \\
Wastewater & 0.74 & 0.87 & 1.10 & 0.0 \\
\hline
\end{tabular}


For all cases involving non-zero contamination angles, higher $\theta_{\text {cap }}$ resulted in experimental $\mathrm{k}_{\mathrm{L}}$ values tending to the Frössling correlation. However, results differ from the literature when the contamination angle is $0^{\circ}$. It is usually assumed that above the $\mathrm{CMC}$, bubbles behave as rigid particles with liquid-side mass transfer 545 coefficients well characterized by the Frössling correlation. In this study, this procedure markedly overestimates $\mathrm{k}_{\mathrm{L}}$. As mentioned above, beyond the CMC, bubble rise velocities are constant and oxygen diffusion coefficients are nearly the same as in water. However, the measured oxygen concentration fields still decreased as the surfactant concentration increased. To reach $\mathrm{k}_{\mathrm{L}}$ values with the Frössling correlation 550 in accordance with experimental liquid-side mass transfer coefficients, smaller diffusion coefficients would be required: $\mathrm{D}=8 \times 10^{-10}, 1 \times 10^{-10}$ and $1 \times 10^{-9} \mathrm{~m}^{2} / \mathrm{s}$ for demineralized water with $0.02 \mathrm{~g} / \mathrm{L}$ and $0.22 \mathrm{~g} / \mathrm{L}$ of caprylate moniglyceride and filtered wastewaters respectively. The Hele-Shaw cell methodology for determining oxygen diffusion coefficients (like other available techniques for determination of this 555 parameter) is not relevant in the presence of surfactants, since measurements are performed hundreds of micrometers away from the interface due to laser reflection and optical resolution considerations. In the range of concentration covered in this study, surfactants tend to congregate at the gas/liquid interface, the rest of the liquid behaving like water. By measuring the diffusion coefficient "far" from the interface, 560 experimental diffusion coefficients are similar to those for an oxygen-water system. Moreover, depending on the caprylate monoglyceride concentration, different diffusion coefficients are required to fit experimental data to the Frössling correlation. This highlights the presence of a surfactant barrier at the gas/liquid interface whose "barrier level" depends on the surfactant concentration, and probably also on the 565 extent of multilayer congregation at the interface. Finally, the higher the surfactant concentration, the thicker the barrier and thus the lower the transfer of oxygen. Waters extracted from sewage plant are subject to the same considerations and conclusions. This highlights the high capacity of surfactants to hinder mass transfer, but also the great care needed if standard equations are to be applied for designing aerated 570 processes in this range of bubble diameters. 


\section{Conclusions}

575

This paper utilizes for the first time efficient visualization techniques developed previously to better understand the mechanisms that locally govern the gas/liquid mass transfer in presence of surfactants in demineralized water and wastewaters. These techniques are focused on oxygen mass transfer (i) from single millimetre-size bubble, rising in a stagnant liquid free from solid particles (two-phase system) and (ii) through a planar oxygen/liquid interface in a Hele-Shaw cell. Results can be summarized as follows

- There is a strong depression in bubble rise velocity in the presence of surfactants, causing higher angles of contamination.

- Bubbles generated in filtered wastewaters and in demineralized water with surfactant concentration higher than the critical micelle concentration (CMC) are fully contaminated.

- Above the CMC, for the surfactants and concentrations tested, the bubble rise was independent of surfactant concentration.

590 - Whatever the contamination angle, the higher the surfactant concentration, the lower the transfer of oxygen to the liquid phase.

- The experimental liquid-side mass transfer coefficient was lower by $80 \%$ for wastewater and by $46 \%$ for treated water than for demineralized water.

- Diffusion coefficients estimated in the bulk liquid, i.e. away from the gasliquid interface, were similar for all liquids tested and equal to that obtained for an oxygen-water system at $20^{\circ} \mathrm{C}$.

- The Frössling correlation with experimental Reynolds and Schimdt numbers, overestimates oxygen mass transfer for fully contaminated bubbles. This overestimation was by a factor of 2 for wastewater.

These results highlight the presence of mass transfer inhibition at the gas/liquid interface, separate from the impact of surfactants on contamination angle and reduction in rising velocity. Since this inhibition is enhanced by increasing surfactant concentration, a congregation of surfactants occurs at the gas/liquid interface providing a barrier to mass transfer. Further experiments focusing at the interface scale are required to provide further understanding of this inhibition effect. It would 
also be interesting to extend this approach to larger bubble diameters which are likely to be affected less by the presence of surfactants.

610

615

620

625

630

635 


\begin{tabular}{|c|c|c|}
\hline $\mathrm{a}$ & Interfacial area & $\mathrm{m}^{2} / \mathrm{m}^{3}$ \\
\hline $\mathrm{C}_{\mathrm{D}}$ & Drag coefficient & \\
\hline $\mathrm{C}_{\mathrm{D}}^{\mathrm{m}}$ & Drag coefficient for a mobile bubble surface & \\
\hline $\mathrm{C}_{\mathrm{D}}^{\mathrm{im}}$ & Drag coefficient for an immobile bubble surface & \\
\hline $\mathrm{D}$ & Oxygen diffusion coefficient & $\mathrm{m}^{2} / \mathrm{s}$ \\
\hline $\mathrm{d}_{\mathrm{eq}}$ & Equivalent bubble diameter & $\mathrm{m}$ \\
\hline $\mathrm{F}$ & Flux of transferred oxygen & $\mathrm{mg} / \mathrm{s}$ \\
\hline $\mathrm{He}$ & Henry's law constant & $\mathrm{Pa}$ \\
\hline I & Fluorescence intensity & - \\
\hline $\mathrm{I}_{0}$ & Fluorescence intensity in absence of oxygen & - \\
\hline $\mathrm{J}$ & Flux density of transferred oxygen & $\mathrm{mg} \cdot \mathrm{s}^{-1} \cdot \mathrm{m}^{-2}$ \\
\hline $\mathrm{k}_{\mathrm{L}}$ & Liquid side mass transfer coefficient & $\mathrm{m} / \mathrm{s}$ \\
\hline $\mathrm{K}_{\mathrm{SV}}$ & Stern-Volmer constant & $\mathrm{L} / \mathrm{mg}$ \\
\hline$\left[\mathrm{O}_{2}\right]$ & Oxygen concentration & $\mathrm{mg} / \mathrm{L}$ \\
\hline$\left[\mathrm{O}_{2}\right]^{*}$ & Oxygen saturation concentration & $\mathrm{mg} / \mathrm{L}$ \\
\hline$\left[\mathrm{O}_{2}\right]_{0}$ & Oxygen concentration in the bulk liquid & $\mathrm{mg} / \mathrm{L}$ \\
\hline $\mathrm{Re}$ & Reynolds number & - \\
\hline $\mathrm{S}_{\mathrm{b}}$ & Bubble surface & $\mathrm{m}^{2}$ \\
\hline Sc & Schimdt number & - \\
\hline $\mathrm{t}$ & time & $\mathrm{s}$ \\
\hline $\mathrm{U}_{\mathrm{b}}$ & Bubble rise velocity & $\mathrm{m} / \mathrm{s}$ \\
\hline $\mathrm{x}$ & Distance to the gas/liquid interface & $\mathrm{m}$ \\
\hline$\theta_{\text {cap }}$ & Contamination angle & $\circ$ \\
\hline$\mu_{\mathrm{L}}$ & Dynamic viscosity in the liquid phase & Pa.s \\
\hline$Q_{\mathrm{L}}$ & Density of the liquid phase & $\mathrm{kg} / \mathrm{m}^{3}$ \\
\hline$\sigma_{\mathrm{L}}$ & Surface tension in the liquid phase & $\mathrm{mN} / \mathrm{m}$ \\
\hline$\chi$ & Bubble aspect ratio & - \\
\hline$\lambda$ & Liquid conductivity & $\mu \mathrm{S} / \mathrm{cm}$ \\
\hline
\end{tabular}




\section{References}

645

Alves, S. S., Orvalho, S. P., and Vasconcelos, J. M. T. (2005). Effect of bubble contamination on rise velocity and mass transfer. Chemical Engineering Science, 60(1), 1-9.

650 ASCE (1992). Standard measurement of oxygen transfer in clean water. American Society ofCivil Engineers.

Bel Fdhila, R. and Duineveld, P. (1996). The effect of surfactant on the rise of a spherical bubble at high reynolds and peclet numbers. Physics of Fluids, 8(2):310 655321.

Chen, J., Kim, H. and Kim, K. (2013). Measurement of dissolved oxygen diffusion coefficient in a microchannel using uv-led induced fluorescence method. Microfluidics and Nanofluidics, 14(3-4):541-550.

660

Clift, R., Grace, J.R., and Weber, M.E. (1978). Bubbles, Drops, and Particles, Academic Press, New York.

665 Crank, J. (1975). The mathematics of diffusion / by J. Crank. Clarendon Press Oxford [England], 2nd ed. édition.

Crimaldi, J. (2008). Planar laser induced fluorescence in aqueous flows. Experiments in fluids, 44(6):851-863.

670

Dani, A., Guiraud, P. and Cockx, A. (2007). Local measurement of oxygen transfer around a single bubble by planar laser-induced fluorescence. Chemical Engineering Science, 62(24):7245-7252.

675 Fick, A. (1855). Ueber diffusion. Annalen der Physik, 170(1):59-86. 
François, J., Dietrich, N., Guiraud, P. and Cockx, A. (2011). Direct measurement of mass transfer around a single bubble by micro-plifi. Chemical Engineering Science, 66(14):3328 - 3338 .

680

Frössling, N. (1938). Uber die verdunstung fallenden tropfen. Gerlans Beitage Geophysik, 52(1):170-216.

Garcia-Ochoa, F., and Gomez, E. (2009). Bioreactor scale-up and oxygen transfer rate 685 in microbial processes: an overview. Biotechnology advances, 27(2), 153-176.

Germain, E., Nelles, F., Drews, A., Pearce, P., Kraume, M., Reid, E. and Stephenson, T. (2007). Biomass effects on oxygen transfer in membrane bioreactors. Water Research, 41(5), 1038-1044.

690

Gillot, S., Capela-Marsal, S., Roustan, M., and Héduit, A. (2005). Predicting oxygen transfer of fine bubble diffused aeration systems-model issued from dimensional analysis. Water research, 39(7), 1379-1387.

695 Hébrard, G., Destrac, P., Roustan, M., Huyard, A., and Audic, J. M. (2000). Determination of the water quality correction factor $\alpha$ using a tracer gas method. Water Research, 34(2), 684-689.

Hébrard, G., Zeng, J., and Loubiere, K. (2009). Effect of surfactants on liquid side 700 mass transfer coefficients: a new insight. Chemical Engineering Journal, 148(1), 132138.

Higbie, R. (1935). The rate of absorption of a pure gas into a still liquid during short periods ofexposure. Trans.Am.Inst.Chem.Eng., 35(1):36-60.

Jablonski, A. (1933). Efficiency of anti-stokes fluorescence in dyes. Nature, 131:839840. 
Jamnongwong, M., Loubière, K., Dietrich, N. and Hébrard, G. (2010). Experimental study of oxygen diffusion coefficients in clean water containing salt, glucose or surfactant: Consequences on the liquid-side mass transfer coefficients. Chemical Engineering Journal, 165(3):758-768.

Jimenez, M., Dietrich, N. and Hébrard, G. (2013a). Mass transfer in the wake of nonspherical air bubbles quantified by quenching of fluorescence. Chemical Engineering Science, 100(0):160-171.

Jimenez, M., Dietrich, N., Cockx, A., and Hébrard, G. (2013b). Experimental study of O2 diffusion coef- ficient measurement at a planar gas liquid interface by planar laser induced fluorescence with inhibition. AIChE Journal, 59(1):325-333.

720 Jimenez, M., Dietrich, N., and Hébrard, G. (2012). A new method for measuring diffusion coefficient of gases in liquids by PLIF. Mod. Phys. Lett. B, 26.

Jirka, G. et al. (2004). Application of lif to investigate gas transfer near the air-water interface in a grid-stirred tank. Experiments in Fluids, 37(3):341-349.

$725 \mathrm{Ju}, \mathrm{L} . \mathrm{K}$. and Sundararajan, A. (1995). The effects of cells on oxygen transfer in bioreactors. Bioprocess Engineering, 13(5), 271-278.

Kück, U., Schlüter, M. and Räbiger, N. (2010). Investigation on reactive mass transfer at freely rising gas bubbles experimental methods for multiphase flows. In Seventh 730 International Conference on Multiphase Flow, Florida, USA.

Kück, U., Schlüter, M. and Räbiger, N. (2012). Local measurement of mass transfer rate of a single bubble with and without a chemical reaction. Journal of Chemical Engineering of Japan, 45(9):708-712.

Loubière, K., and Hébrard, G. (2004). Influence of liquid surface tension (surfactants) on bubble formation at rigid and flexible orifices. Chemical Engineering and Processing: Process Intensification, 43(11), 1361-1369.

740 Mei, R., Klausner, J. F. and Lawrence, C. J. (1994). A note on the history force on a spherical bubble at finite reynolds number. Physics of fluids, 6:418. 
Painmanakul, P., Loubière, K., Hébrard, G., Mietton-Peuchot, M., and Roustan, M. (2005). Effect of surfactants on liquid-side mass transfer coefficients. Chemical 745 Engineering Science, 60(22), 6480-6491.

Redmond, D. T., Boyle, W. and Ewing, L. (1983). Oxygen transfer efficiency measurements in mixed liquor using off-gas techniques. J.Water Pollut. Control Fed., (55):1338-1347.

750

Robert, C. P. and Casella, G. (1999). Monte Carlo Statistical Methods. SpringerVerlag, New York.

Rosso, D., Iranpour, R., and Stenstrom, M. K. (2005). Fifteen years of offgas transfer 755 efficiency measurements on fine-pore aerators: Key role of sludge age and normalized air flux. Water environment research, 266-273.

Rosso, D., Huo, D. L., and Stenstrom, M. K. (2006a). Effects of interfacial surfactant contamination on bubble gas transfer. Chemical engineering science, 61(16), 55007605514

Rosso, D., and Stenstrom, M. K. (2006b). Surfactant effects on $\alpha$ factors in aeration systems. Water research, 40(7), 1397-1404.

765 Roustan, M. (2003). Transferts Gaz-liquide Dans Les Procédés De Traitement Des Eaux Et Des Effluents Gazeux. Tec et Doc.

Sadhal, S. and Johnson, R. E. (1983). Stokes flow past bubbles and drops partially coated with thin films. part 1. stagnant cap of surfactant film-exact solution. Journal of Fluid Mechanics, 126(1):237-250.

Sardeing, R., Painmanakul, P., and Hébrard, G. (2006). Effect of surfactants on liquid-side mass transfer coefficients in gas-liquid systems: a first step to modeling. Chemical engineering science, 61(19), 6249-6260. 
Schiller, L. and Naumann, A. Z. (1933). Über die grundlegenden Berechnungen bei der Schw- erkraftaufbereitung. Ver. Deut. Ing., 77:318-320.

Scheibel, E. G. (1954). Physical chemistry in chemical engineering design. Industrial 780 and Engineer- ing Chemistry, 46(8):1569-1579.

Vasconcelos, J. M., Orvalho, S. P., and Alves, S. S. (2002). Gas-liquid mass transfer to single bubbles: effect of surface contamination. AIChE journal, 48(6), 1145-1154.

785 Vasconcelos, J. M. T., Rodrigues, J. M. L., Orvalho, S. C. P., Alves, S. S., Mendes, R. L., and Reis, A. (2003). Effect of contaminants on mass transfer coefficients in bubble column and airlift contactors. Chemical Engineering Science, 58(8), 1431-1440.

Wilke, C. R. and Chang, P. (1955). Correlation of diffusion coefficients in dilute 790 solutions. AIChE Journal, 1(2):264-270.

Zhang, Y., Sam, A. and Finch, J. (2003). Temperature effect on single bubble velocity profile in water and surfactant solution. Colloids and Surfaces A: Physicochemical and Engineering Aspects, 223(1-3):45-54. 